\title{
Message from the 2020 Program Chair
}

Published online: 10 November 2020

(C) International Association of Medical Science Educators 2020
Dear Colleagues,

The $24^{\text {th }}$ annual meeting of the International Association of Medical Science Educators offered us a unique opportunity to connect virtually in response to the COVID-19 pandemic. I was honored to work with the members of the 2020 Program Planning Committee, the IAMSE leadership, and our IAMSE management company JulNet to host the very first virtual annual meeting of IAMSE!

Our conference theme: "Scaling New Heights: Envisioning the Future of Health Sciences Education" was supported by our plenary speakers, which included: Dr. Cynthia Nebel who spoke on the application of cognitive psychology to improve teaching and learning, Dr. Renay Scales, who spoke on cultivating diversity and inclusion in medical education, Dr. Maria Mylopoulos, who spoke on cognition, curriculum and adaptive expertise to prepare future experts, and Dr. Poh Sun Goh, who spoke on medical educator roles of the future.

Of special note, we held the first student-led plenary titled "Envisioning the Future of Health Sciences Education Across Different Healthcare Professions Worldwide", which featured four students from different health professions schools in the Netherlands and the U.S. The students shared their personal views and experience on topics that included diversity and implicit bias in medical education, drivers of change in health professions education, changes in the Dutch dentistry program to cope with changing times, and embracing a growth mindset to create solutions for clinical problems. We are excited to share the students' meeting report in this issue of Medical Science Educator.
In addition to these highlights, the virtual meeting included online oral and poster presentations, social/networking opportunities, virtual exhibit halls, recognition of our award winners, our annual IAMSE business meeting, and a presentation by Dr. Mark Hernandez, Chair of the 2021 Program Planning Committee featuring the 2021 conference.

I'd also like to recognize our IAMSE Award recipients, Dr. Carol Nichols who received the IAMSE Distinguished Career Award for Excellence in Teaching and Educational Scholarship, Dr. Amber Heck who received the IAMSE Early Career Award for Excellence in Teaching and Innovation, Dr. Giulia Bonaminio who received the Edward Patrick Finnerty Lifetime Achievement Award, and Michael Healy and Jessica Carlson, who received the awards for the best Oral and Poster Presentations, respectively. These awards represent the outstanding accomplishments and contributions of our faculty and student members.

In closing, on behalf of the 2020 Program Planning Committee and the IAMSE leadership and staff, I'd like to thank you, our IAMSE members, for your contributions to the 2020 meeting and your unwavering support of IAMSE. I look forward to when we can all be together again to share our journey as educators and scholars dedicated to advancing health profession education.

Bonny Dickinson, PhD, MS-HPEd

2020 Chair of the IAMSE Program Planning Committee

Publisher's Note Springer Nature remains neutral with regard to jurisdictional claims in published maps and institutional affiliations. 